\title{
Nitric oxide decomposition on small rhodium clusters,
}

$$
\mathrm{Rh}_{n}^{+/-}
$$

Marie L. Anderson ${ }^{a}$, Mark S. Ford ${ }^{a}$, Peter J. Derrick ${ }^{a}$, Thomas Drewello ${ }^{a}$, D. Phil Woodruff ${ }^{b}$, and Stuart R. Mackenzie ${ }^{a, *}$

${ }^{a}$ Department of Chemistry, University of Warwick, Coventry, CV4 7AL, United Kingdom,

${ }^{\mathrm{b}}$ Department of Physics, University of Warwick, Coventry, CV4 7AL, United Kingdom

*corresponding author, current address: Department of Chemistry, University of Cambridge, Cambridge, CB2 1EW, UK. Email: srm49@cam.ac.uk

TITLE RUNNING HEAD: NO decomposition on $\mathrm{Rh}_{n}{ }^{+/-}$clusters

KEYWORDS: FT-ICR, rhodium, metal clusters, catalytic converter, nitric oxide, decomposition, laser ablation 


\section{Abstract}

The decomposition of nitric oxide on small charged rhodium clusters $\mathrm{Rh}_{n}{ }^{+/}(6<n<30)$ has been investigated by Fourier transform ion cyclotron resonance mass spectrometry. For both cationic and anionic naked clusters, the rates of reaction with NO increase smoothly with cluster size in the range studied without the dramatic size-dependent fluctuations often associated with the reactions of transition metal clusters. The cationic clusters react significantly faster than the anions and both exhibit rate constants exceeding collision rates calculated by average dipole orientation theory. Both the approximate magnitude and the trends in reactivity are modeled well by the surface charge capture model recently proposed by Kummerlöwe and Beyer. All clusters studied here exhibit pseudo first order kinetics with no evidence of bi-exponential kinetics often interpreted as evidence for multiple isomeric structures. Experiments involving prolonged exposure to NO have revealed interesting size-dependent trends in the mechanism and efficiency of NO decomposition: For most small clusters $(n<17)$, once two NO molecules are co-adsorbed on a cluster, $\mathrm{N}_{2}$ is evolved generating the corresponding dioxide cluster. By analogy with experiments on extended surfaces, this observation is interpreted in terms of the dissociative adsorption of NO in the early stages of reaction generating $\mathrm{N}$ atoms which are mobile on the surface of the cluster. For clusters $n<13$ this chemistry, which occurs independently of the cluster charge, repeats until a size-dependent, limiting oxygen coverage is achieved. Following this, NO is observed to adsorb on the oxide cluster without further $\mathrm{N}_{2}$ evolution. For $n=14-16$ no single end-point is observed and reaction products are based on a small range of oxide structures. By contrast, no evidence for $\mathrm{N}_{2}$ production is observed for clusters $n=13$ and $n>16$ for which simple sequential NO adsorption dominates the chemistry. Interestingly, there is no evidence for the production of $\mathrm{N}_{2} \mathrm{O}$ or $\mathrm{NO}_{2}$ on any of the clusters studied. A simple general mechanism is proposed which accounts for all observations. The detailed 
decomposition mechanisms for each cluster exhibit size- (and, by implication, structure-) dependent features with $\mathrm{Rh}_{13}{ }^{+/-}$particularly anomalous by comparison with neighboring clusters.

\section{Introduction}

At the heart of many heterogeneous catalytic processes lie highly dispersed transition metals. In this form they not only present increased surface area but also maximize the number of surface defect sites which are believed to be crucial in providing the active sites for interesting chemistry. ${ }^{1}$ Over the past two decades intense effort has been directed towards the study of small metal clusters in the belief that these clusters, in addition to exhibiting fascinating properties of their own, represent tractable model systems for practical catalysts. ${ }^{2,3}$ In this spirit we present here a detailed experimental study of an industrially and environmentally important system, the decomposition of nitric oxide on rhodium clusters.

Rhodium is an important heterogeneous catalyst, employed both in hydrogenation and dehydrogenation reactions relating to alcohols ${ }^{4}$ as well as in the reduction of harmful gases. ${ }^{5}$ The catalytic reduction of $\mathrm{NO}_{\mathrm{X}}$ by platinum and rhodium plays a key role in the chemistry of the automobile three-way catalytic converter. As a result of its practical importance the reduction of nitric oxide at transition metal surfaces has been widely investigated due to its importance in industrial pollution control processes ${ }^{6-10}$ and has been the subject of a recent review by Brown and King. ${ }^{11}$

The remarkable activity of rhodium surfaces for adsorption and reduction of NO has received particular attention from the surface science community. ${ }^{1,6-8,12-29}$ The relatively small NO bond energy leads to a greater degree of dissociation for surface adsorbed nitric oxide than is commonly 
seen for other adsorbates such as CO. Spectroscopic studies have shown that the degree of NO dissociation depends critically on surface temperature and coverage as well as the exact crystal face. $^{15,16,22-28,30-36}$ At low temperatures $(\mathrm{T}<170 \mathrm{~K}) \mathrm{NO}$ adsorbs molecularly on all Rh surfaces. When present at low coverages, NO dissociates completely upon heating resulting in the desorption of the dissociation products $\mathrm{N}_{2}(450 \mathrm{~K}<\mathrm{T}<700 \mathrm{~K})$ and $\mathrm{O}_{2}$ (at much higher temperatures). ${ }^{15,17,25}$ NO dissociation requires an empty nearest neighbour site and so at higher surface coverage dissociation is impeded. At temperatures $<800 \mathrm{~K}$, oxygen atoms produced in NO decomposition typically remain on the surface or diffuse into the bulk. ${ }^{23,37}$ As a result oxygen on the surface can readily poison catalytic activity by hindering further NO adsorption and/or dissociation.

Small quantities of $\mathrm{N}_{2} \mathrm{O}$ and $\mathrm{NO}_{2}$ have been detected desorbing from rhodium surfaces during NO reduction, ${ }^{12}$ especially at higher coverages and higher temperatures. This is particularly important from an environmental perspective as $\mathrm{N}_{2} \mathrm{O}$ is a potent greenhouse gas and therefore its production is undesirable. The problem is exacerbated in oxygen rich environments in which desorption of $\mathrm{N}_{2} \mathrm{O}$ becomes increasingly dominant over $\mathrm{N}_{2}$ production and practical catalysts become unable to cleanly reduce NO. ${ }^{12}$

Fourier transform ion cyclotron resonance (FT-ICR) mass spectrometry has been used to study the reactions of many metal clusters. Due to the presence of only a single naturally occurring isotope, ${ }^{103} \mathrm{Rh}$, rhodium, together with vanadium, cobalt and niobium, has been something of a favorite transition metal for study by mass spectrometry. Among the reactions of rhodium clusters studied by FT-ICR are those with $\mathrm{CO}, \mathrm{N}_{3} \mathrm{CH}_{2} \mathrm{CN}$, benzene and small alkanes. ${ }^{38-41}$ These studies have discovered interesting size-dependent trends in the reaction rates and mechanisms. For example, in the reactions of cationic rhodium clusters with benzene, Berg et al. observed dissociative chemisorption accompanied by total or partial dehydrogenation in competition with nondissociative adsorption for $n \leq 18$. For larger clusters, $n>18$, only the molecular adsorption was observed. ${ }^{40}$ 
The nature of the adsorption of $\mathrm{CO}$ on small rhodium clusters has been studied by Fielicke et al. in exquisite infrared - multiple photon dissociation (IR-MPD) experiments in which a free electron laser is used to excite the internal $\mathrm{CO}$ stretch in $\mathrm{Rh}_{n} \mathrm{CO}^{+/ 0 /-}$ clusters. The experiments are coupled with DFT calculations to probe the binding of the CO. ${ }^{42}$ FT-ICR studies have demonstrated the adsorption of a CO molecule for $n \geq 2$ for the cationic clusters and $n \geq 4$ for the anions, with little difference between the reactivities of anions and cations. ${ }^{38}$ All anionic and large cationic rhodium clusters react with azidoacetonitrile by adding $\left[\mathrm{C}_{2}, \mathrm{~N}_{2}\right]$ in consecutive steps whereas small cationic clusters behave differently, with the unimolecular decomposition of the azide determining the reactivity. ${ }^{39}$ A recent FT-ICR study of $\mathrm{C}-\mathrm{H}$ activation of alkanes on rhodium cationic clusters demonstrated large size dependent variations in reaction efficiency. These rates proceed close to the theoretical collision rates for a large number of clusters with distinct minima observed for particular sizes. ${ }^{41}$ In a separate study, the dehydrogenation of ethane by $\mathrm{Rh}_{n}{ }^{+}$clusters also demonstrated strong size dependence. ${ }^{43}$

In other FT-ICR studies, argon complexes of rhodium clusters, $\mathrm{Rh}_{n} \mathrm{Ar}_{m}{ }^{+}$, undergo ligand exchange reactions with methane, in which up to three argon atoms are replaced. ${ }^{44}$ The solvated dimer and trimer cations dehydrogenate methane with an efficiency dependent on the number of argon atoms. Koszinowski et al. also found dehydrogenation of methane by the rhodium dimer with the subsequent carbene product reacting with ammonia to form $\mathrm{Rh}_{2} \mathrm{C}^{+}\left(\mathrm{NH}_{3}\right) .{ }^{45}$ Whereas cluster size has a significant effect on cluster reactivity, in most cases for a given cluster size both anionic and cationic clusters tend to exhibit a similar reactivity. ${ }^{3,46,47}$

The rates of reaction of charged clusters with small molecules are usually calculated by the average dipole orientation theory ${ }^{48}(\mathrm{ADO})$ which considers the classical trajectory of a linear dipole in the field of a point charge and reduces to the Langevin rate in the limit of negligible dipole moment. However, the rates of reaction for charged metal clusters often significantly exceed those 
calculated by ADO theory. ${ }^{39,49}$ In an attempt to address this issue, Kummerlöwe and Beyer have recently presented two models for calculating collision rates of ionic clusters with neutral molecules. Both models treat the cluster and the neutral reaction partner as hard spheres and the charge is treated as a point charge. The attraction between the point charge and the neutral molecule is described with the interaction potential from ADO theory. In the Surface Charge Capture (SCC) model the charge is free to migrate to the surface of the cluster, drawn there by the attractive interation with the neutral molecule. The SCC model leads to substantially increased collision rates compared with Langevin or ADO capture rates. However, even the increased rates obtained with these models are exceeded by the measured reaction rates of some reactions, e.g., $\mathrm{Rh}_{n}{ }^{+/-}$with $\mathrm{CO} .{ }^{49}$

Here we present the results of FT-ICR studies of the reactivity of charged rhodium clusters, $\mathrm{Rh}_{n}{ }^{+/}$, $n=7-30$, with NO. We have previously published a study of $\mathrm{Rh}_{6}{ }^{+}$with NO which was unique in exhibiting evidence for two different structural isomers. ${ }^{50}$ In this paper we concentrate on the trends in reactivity and mechanism with cluster size.

\section{Experimental methods}

All experiments were performed on a Bruker FT-ICR mass spectrometer equipped with a 3 T superconducting magnet and an external laser ablation cluster source. The source is fitted with an additional pumping stage to allow the operation of a pulsed molecular beam while maintaining a low pressure in the ICR cell region. The cluster source is a slightly modified version of the laser ablation cluster source developed in Munich, the details of which have been published elsewhere. ${ }^{51}$ In essence it is also similar to the source developed independently by Alford et al. ${ }^{46}$

Briefly, charged rhodium clusters, $\mathrm{Rh}_{\mathrm{n}}{ }^{+/}, n=7-30$, are produced by the pulsed laser vaporization (typically $3 \mathrm{~mJ}, 532 \mathrm{~nm}, 8 \mathrm{~ns}$ pulse) of a rotating rhodium disc (12 mm diam., $0.25 \mathrm{~mm}$ thick, Aldrich). The resulting metal-containing plasma is entrained in a ca. $30 \mu$ s pulse of helium carrier 
gas (BOC, 99.997\%, 30 bar backing pressure) delivered via a homebuilt piezoelectric valve operating in synchronization with the laser at $10 \mathrm{~Hz}$. To facilitate clustering, the beam travels through a channel (50 $\mathrm{mm}$ long, $2 \mathrm{~mm}$ diameter) before expanding into the source chamber. The pressure in this chamber is maintained at a pressure of $10^{-7} \mathrm{mbar}$, rising to almost $10^{-4} \mathrm{mbar}$ during pulsing. The resulting cluster ion beam passes through a $0.5 \mathrm{~mm}$ diameter skimmer into a series of differentially pumped chambers containing ion transfer optics which focus the charged clusters into the ICR infinity cell, maintained at a base pressure of $c a .2 \times 10^{-10} \mathrm{mbar}$, where they are trapped axially by a $1.5 \mathrm{~V}$ trapping potential applied to the ends of the cell. For the experiments performed here, the major advantage of FT-ICR, in addition to its high resolution, is the extended time for which the ions can be trapped within the ICR cell which permits the sequential adsorption of multiple reactant molecules.

The efficiency of the cluster ion formation and the size distribution of the clusters generated (typically 10-15 rhodium atoms broad) can be crudely controlled by varying the experimental conditions such as the laser fluence, the stagnation pressure of the carrier gas and, in particular, the relative timing of the valve and the firing of the ablation laser. The optimal conditions for generating anionic and cationic clusters were found to be essentially identical and switching from storing one to the other is simply a matter of reversing the polarity of potentials applied to the ion transfer optics. In this way rhodium clusters, $\mathrm{Rh}_{n}{ }^{+-}, n=6-30$ can be generated and trapped with high efficiency. In order to increase the signal to noise ratio, however, clusters from up to 20 laser pulses are typically accumulated in the ICR cell prior to reaction.

To study the reactions of clusters stored within the ICR cell, nitric oxide (Argo International, $99.5 \%$ ) was admitted via a leak valve to maintain cell pressures in the region $10^{-9}-10^{-8}$ mbar as measured on the ion gauge nearest the ICR cell. It is notoriously difficult in such experiments to determine the exact pressure in the ICR cell as the ion gauge is located a considerable distance ( $c a$. 
$0.8 \mathrm{~m}$ ) from the cell itself, inconveniently close to both the leak valve input and to the main turbomolecular pump evacuating the cell. As a result there is likely to be some consistent discrepancy between the gauge reading and the actual cell pressure. In an attempt to calibrate our cell pressure we have adopted the methodology described by Laskin et al.: ${ }^{52}$ Calibration studies were performed in situ using the well-characterised charge transfer reaction $\mathrm{Ar}+\mathrm{N}_{2}{ }^{+}$,

$$
\mathrm{Ar}+\mathrm{N}_{2}^{+}(v=1) \rightarrow \mathrm{Ar}^{+}+\mathrm{N}_{2}
$$

utilising the instrument's internal electron impact ionization source and a pulse of $\mathrm{N}_{2}$ gas. The rate constant for this reaction, $4 \times 10^{-10} \mathrm{~cm}^{3} \mathrm{~s}^{-1}$, is well known from selective ion flow measurements. ${ }^{53}$ Comparison of the observed rates with the above value yields an effective geometry factor for our instrument $(4.28 \pm 0.87)$ by which the measured pressures can be corrected. The pressure corrections also took account of the well known differing gauge sensitivities to different gases. All pressures quoted below have been corrected in the above manner. Nevertheless, in common with other studies of this type we estimate the net uncertainty in our absolute rate constants is approximately $\pm 50 \%{ }^{49}$ The relative reaction rates for different cluster sizes and charges, however, are very much better determined than this.

The kinetics of the $\mathrm{Rh}_{n}^{+/-}+\mathrm{NO}$ reaction are determined by analysis of the mass spectra obtained after variable reaction times. The raw mass spectra are baseline corrected and all peaks arising from a given cluster are integrated and intensity normalised within a given parent cluster, reaction product manifold. In order to determine as precisely as possible relative rates of reaction of different clusters, most experiments were performed without isolation. Due to the extensive chemistry observed it was necessary to repeat experiments for isolated clusters and indeed isolated intermediate products in order to determine with confidence the mechanisms of reaction of individual cluster sizes. In such 
experiments correlated frequency sweeps were used to remove all other ions from the cell. Careful checks were made to ensure that the kinetics were identical with and without isolation. Similar isolation experiments were performed to ensure that cluster fragmentation is insignificant as a channel in any of the experiments performed.

For these studies no attempt was made to thermalise the clusters prior to reaction with nitric oxide and no kinetic evidence for multiple isomers was observed (all pseudo-first order kinetic plots showed good approximation to linearity). This contrasts markedly with the results of reactive studies of $\mathrm{Rh}_{n}{ }^{+}$clusters with $\mathrm{N}_{2} \mathrm{O}$ performed in our group. ${ }^{54}$

The ion molecule reactions we observe can best be described as near-thermal. The trapping of the cluster ions within the ICR cell by $1.5 \mathrm{~V}$ trapping potentials sets an upper limit on their initial translational energy. For a $\mathrm{Rh}_{n}^{+/-}+\mathrm{NO}$ collision, this gives rise to a centre of mass collision energy in the range of $60 \mathrm{meV}$ for $n=7$ to $14 \mathrm{meV}$ for $n=30$. The internal energy of the clusters is unknown but is assumed to be small (i.e., the clusters are effectively cooled) given the nature of the expansion conditions. On extended rhodium surfaces the NO adsorption energy is typically $c a .-2.2$ $\mathrm{eV}^{19}$ suggesting molecular adsorption of NO to the metal cluster will cause substantial heating due to the limited number of vibrational degrees of freedom. Dissociative adsorption results in more heating due to the $\mathrm{O}$ and $\mathrm{N}$ atom binding energies (ca. $4.8 \mathrm{eV}$ each on $\mathrm{Rh}(100)^{19}$ ). As a result, subsequent reactions must compete with other processes such as radiative cooling. We observe such effects indirectly in differing branching ratios for various reactions at different pressures. 


\section{Results and Discussion}

\subsection{Overview of the decomposition mechanism}

By way of illustration of the raw data obtained, Figure 1 shows time evolution of the mass spectra of $\mathrm{Rh}_{11}{ }^{+}$clusters exposed to $8.6 \times 10^{-9}$ mbar nitric oxide. The reaction of this particular cluster demonstrates the key features representative of most sizes studied and thus it is illustrative to discuss the mechanism in detail.

\section{Insert Fig. 1 near here}

The first step in the reaction is the addition of a single NO molecule to the naked cluster generating $\left[\mathrm{Rh}_{11} \mathrm{NO}\right]^{+}$. After 2 seconds at this pressure, the following products can be unambiguously assigned: $\left[\mathrm{Rh}_{11} \mathrm{NO}\right]^{+},\left[\mathrm{Rh}_{11} \mathrm{O}_{2}\right]^{+},\left[\mathrm{Rh}_{11}(\mathrm{NO})_{2}\right]^{+}$and $\left[\mathrm{Rh}_{11} \mathrm{O}_{2} \mathrm{NO}\right]^{+}$. It is important to note that all species are identified on the basis of their mass alone- i.e., no direct information is obtained as to the nature of the adsorption (molecular vs dissociative). We adopt the convention of square brackets to indicate this; the molecular formula as written within is merely for convenience within the context of the mechanism presented below. It is, however, possible to infer the likely nature of the adsorption by consideration of the other reaction products and a plausible reaction mechanism. We interpret the observation of the $\left[\mathrm{Rh}_{11} \mathrm{O}_{2}\right]^{+}$product as resulting from the rapid decomposition of the $\left[\mathrm{Rh}_{11}(\mathrm{NO})_{2}\right]^{+}$ species liberating $\mathrm{N}_{2}$. This suggests that in the early stages of the reaction the NO is dissociatively adsorbed and that the nitrogen atoms have sufficient mobility across the surface of the cluster to rapidly find each other. Except at low temperatures $(\mathrm{T}<160 \mathrm{~K}$ on $\mathrm{Rh}(001)$ and $\mathrm{T}<250 \mathrm{~K}$ on $\mathrm{Rh}(111))$, NO dissociatively adsorbs on all common rhodium surfaces with $\mathrm{N}_{2}$ being desorbed at substantially lower temperatures than $\mathrm{O}_{2} .{ }^{11}$ Several density functional theory studies also support this picture..$^{20,23,37}$ Although the initial internal energy (or "temperature") of the clusters in the present study is unknown, as discussed above the exoergicity of adsorption of even a single NO 
molecule is likely to result in substantial vibrational heating of the cluster. On the smallest clusters $(\mathrm{n}<9)$, the decomposition / desorption reaction proceeds sufficiently quickly that the $\left[\mathrm{Rh}_{n}(\mathrm{NO})_{2}\right]^{+}$ intermediate is not observed on the timescale of the FT-ICR experiment. ${ }^{55}$ This is consistent with the fact that the two NO molecules adsorbing will have proportionately larger "heating" effect on a smaller cluster than on a larger cluster with more vibrational degrees of freedom within which to accommodate the energy. It is reasonable to assume that the formation and subsequent desorption of $\mathrm{N}_{2}$ requires some mobility on the part of nitrogen atoms. The fact that the $\left[\mathrm{Rh}_{n}(\mathrm{NO})_{2}\right]^{+}$intermediate is observed for the larger clusters $(n \geq 9)$, (see, for example the clear $\left[\mathrm{Rh}_{11}(\mathrm{NO})_{2}\right]^{+}$product in reactions of $\mathrm{Rh}_{11}{ }^{+}$, Figure 1) suggests either that in some cases at least one of the NO molecules fails to dissociate upon adsorption or that the cluster cools sufficiently quickly (e.g., radiatively) for the combinative desorption of $\mathrm{N}_{2}$ to be no longer possible. We attempted to observed the $\left[\mathrm{Rh}_{11}(\mathrm{NO})_{2}\right]^{+}$ $\rightarrow\left[\mathrm{Rh}_{11} \mathrm{O}_{2}\right]^{+}+\mathrm{N}_{2}$ decomposition directly by mass-selecting the $\left[\mathrm{Rh}_{11}(\mathrm{NO})_{2}\right]^{+}$intermediate product but such efforts were unsuccessful implying that both the decomposition and the radiative cooling are considerably faster than the FT-ICR timescale.

Following formation of the dioxide cluster, the next product to appear, $\left[\mathrm{Rh}_{11} \mathrm{O}_{2} \mathrm{NO}\right]^{+}$, clearly arises from the adsorption of a further NO molecule and the whole decomposition process repeats such that after 5 seconds a range of $\left[\mathrm{Rh}_{11} \mathrm{O}_{y}(\mathrm{NO})_{x}\right]^{+}$products are observed in the mass spectrum. There is clear evidence for decomposition, marked by the apparent loss of $\mathrm{N}_{2}$, whenever at least two NO molecules are co-adsorbed. This decomposition results in the sequential formation of the dioxide, tetroxide and hexaoxide clusters. Figure 2 shows a close up of the mass spectra recorded after 5 seconds together with a cartoon of the principal decomposition pathways.

\section{Insert Fig 2 near here}


Upon the formation of $\left[\mathrm{Rh}_{11} \mathrm{O}_{6}\right]^{+}, \mathrm{N}_{2}$ loss apparently ceases and further reactions are characterized by the sequential adsorption of NO until the cluster reaches a saturation point beyond which no further reaction occurs. For $\mathrm{Rh}_{11}{ }^{+/}$at this pressure the largest product observed is $\left[\mathrm{Rh}_{11} \mathrm{O}_{6}(\mathrm{NO})_{11}\right]^{+}$.

By using careful product isolation experiments we have derived the following simple mechanism which is consistent with all observations for the reaction with the $\mathrm{Rh}_{11}{ }^{+}$cluster:

$$
\begin{aligned}
& \mathrm{Rh}_{11}{ }^{+} \stackrel{+\mathrm{NO}}{\longrightarrow}\left[\mathrm{Rh}_{11} \mathrm{NO}\right]^{+} \stackrel{+\mathrm{NO}}{\longrightarrow}\left[\mathrm{Rh}_{11}(\mathrm{NO})_{2}\right]^{+} \\
& {\left[\mathrm{Rh}_{11}(\mathrm{NO})_{2}\right]^{+} \longrightarrow\left[\mathrm{Rh}_{11} \mathrm{O}_{2}\right]^{+}+\mathrm{N}_{2}} \\
& {\left[\mathrm{Rh}_{11}(\mathrm{NO})_{2}\right]^{+} \stackrel{+\mathrm{NO}}{\longrightarrow}\left[\mathrm{Rh}_{11}(\mathrm{NO})_{3}\right]^{+}} \\
& {\left[\mathrm{Rh}_{11}(\mathrm{NO})_{3}\right]^{+} \longrightarrow\left[\mathrm{Rh}_{11} \mathrm{O}_{2} \mathrm{NO}\right]^{+}+\mathrm{N}_{2}} \\
& {\left[\mathrm{Rh}_{11} \mathrm{O}_{2}\right]^{+} \stackrel{+\mathrm{NO}}{\longrightarrow}\left[\mathrm{Rh}_{11} \mathrm{O}_{2} \mathrm{NO}\right]^{+} \stackrel{+\mathrm{NO}}{\longrightarrow}\left[\mathrm{Rh}_{11} \mathrm{O}_{2}(\mathrm{NO})_{2}\right]^{+}} \\
& {\left[\mathrm{Rh}_{11} \mathrm{O}_{2}(\mathrm{NO})_{2}\right]^{+} \longrightarrow\left[\mathrm{Rh}_{11} \mathrm{O}_{4}\right]^{+}+\mathrm{N}_{2}} \\
& {\left[\mathrm{Rh}_{11} \mathrm{O}_{4}\right]^{+} \stackrel{+\mathrm{NO}}{\longrightarrow}\left[\mathrm{Rh}_{11} \mathrm{O}_{4} \mathrm{NO}\right]^{+} \stackrel{+\mathrm{NO}}{\longrightarrow}\left[\mathrm{Rh}_{11} \mathrm{O}_{4}(\mathrm{NO})_{2}\right]^{+}} \\
& {\left[\mathrm{Rh}_{11} \mathrm{O}_{4}(\mathrm{NO})_{2}\right]^{+} \longrightarrow\left[\mathrm{Rh}_{11} \mathrm{O}_{6}\right]^{+}+\mathrm{N}_{2}} \\
& {\left[\mathrm{Rh}_{11} \mathrm{O}_{6}\right]^{+} \stackrel{+\mathrm{NO}}{\longrightarrow}\left[\mathrm{Rh}_{11} \mathrm{O}_{6}(\mathrm{NO})\right]^{+} \stackrel{+\mathrm{NO}}{\longrightarrow} \ldots \stackrel{+\mathrm{NO}}{\longrightarrow}\left[\mathrm{Rh}_{11} \mathrm{O}_{6}(\mathrm{NO})_{11}\right]^{+}}
\end{aligned}
$$

This mechanism is generalized for all clusters below but at this point it is worth re-emphasising that we have observed no qualitative difference in the reactions of the anions compared to the cations. They appear to follow the same mechanism albeit exhibiting slightly different rates (see below) and as far as we can ascertain the largest products observed at any given pressure are the same. This is consistent with some previous work on other metal clusters: The reactions of niobium clusters with deuterium and the reactions of niobium and rhodium clusters with benzene, studied by 
Berg et al. showed little charge dependence as did the infra-red studies of $\mathrm{CO}$ on rhodium clusters by Fielicke et al.. $2,38,42,56,57$

\subsection{Step 1: Reactivity of the naked cluster ions}

Figure 3 shows a semi-logarithmic plot of the decay of the bare $\mathrm{Rh}_{11}{ }^{+}$and $\mathrm{Rh}_{11}{ }^{-}$cluster population as a function of reaction time. The good fits to straight lines confirm the pseudo first order nature of the reaction which in turn reflects the excess of NO present. All cluster sizes studied here react with a single exponential decay such as the one given for $n=11$ in Figure 3. Deviation from single exponential decay, especially bi-exponential decay, has previously been interpreted in terms of the presence of multiple isomers (or indeed different cluster spin-states) with different reactivities. ${ }^{50}$ However, in order to observe a noticeably bi-exponential decay there must i) be a significant difference in the reactivity of the different forms and ii) a significant population of each. It is possible that in the reactions with the radical NO, electronic factors govern the reactivity and that the geometrical structure plays a minor role. Reactivity studies of rhodium clusters with closed-shell $\mathrm{N}_{2} \mathrm{O}$ exhibit non-linear pseudo first order plots for a number of clusters within this size range. ${ }^{54}$

\section{Insert Fig. 3 near here}

The pseudo first order rate constants derived from the slopes of the first order kinetic plots can be used to determine the absolute rate constants. These are shown as a function of cluster size for both anionic and cationic clusters in Figure 4. Also shown are the calculated rate constants calculated based on geometrical hard sphere cross-sections and classical ADO theory, as well as the hard 
sphere averaged dipole orientation (HSA) and surface charge capture (SCC) models recently introduced by Kummerlöwe and Beyer. ${ }^{49}$

Several conclusions can be drawn from the observed rate constants collated in Figure 4. Firstly, the variation in the reaction rate with cluster size is rather smooth. There is no evidence of the dramatic size-dependent fluctuations which characterize the reactions of many transition metal clusters with small molecules. ${ }^{44,47,51,58}$ This too may reflect a dominance of electronic effects in determining the reaction rate for this charge + radical system and the relatively small role played by geometrical structure which changes dramatically from size to size. The variation in reaction rate constant with cluster size is more gentle in the present case ( $\sim 50 \%$ increase from $n=7$ to $n=30$ for cations, $\sim 30 \%$ for anions) than in the reactions with $\mathrm{CO}(>400 \%$ and $\sim 80 \%$, respectively). Reactions of rhodium clusters with benzene and azidoacetonitrile demonstrate small fluctuations in relative rates with cluster size $e^{39,40}$ whilst dramatic size fluctuations have been seen in reactions with alkanes. ${ }^{41}$ Secondly, the cationic clusters react typically ca. $25 \%$ faster than do the corresponding anions for all sizes studied. In previous studies of $\mathrm{Rh}_{n}{ }^{+/-}$with $\mathrm{CO}$ the same was true of the very largest clusters studied $(n>20) .{ }^{42}$ In the current experiments, anion and cation clusters are produced under identical source conditions, the only difference being the polarity of the potentials applied to the ion transfer optics and cell trapping potentials. Hence, the simplest assumption is that the internal energy distributions of the cations and anions are similar. However anions have an additional cooling channel available - the loss of an electron - which, if significant, would preferentially deplete the internally excited clusters formed leading to a colder remaining distribution being trapped in the ICR cell.

Finally, the measured rate constants are large - approximately a factor of 3-4 greater than those calculated by classical ADO theory. The observed rates are predicted much more reliably by the surface charge capture model introduced by Kummerlöwe and Beyer ${ }^{49}$ which treats the cluster as a 
perfectly conducting sphere and permits the charge to migrate to the surface under the influence of the neutral molecule. This model yields significantly larger calculated cross-sections than previous models resulting in rate constants consistent with the values measured here given the uncertainty in the experimental values discussed in Section 2 above.

\section{Insert Fig 4 near here}

\subsection{Overall reaction mechanism}

The reaction of rhodium clusters with NO can be well described by the overall mechanism given in Figure 5. The differences between reactions on the various clusters arise from differing branching ratios for $\mathrm{N}_{2}$ evolution versus further $\mathrm{NO}$ adsorption following the formation of $\left[\mathrm{Rh}_{n} \mathrm{O}_{\mathrm{y}}(\mathrm{NO})_{2}\right]^{+/-}(y=$ $0,2,4,6$, etc.) intermediates. These branching ratios are shown schematically in the Figure 5 a-e. Table 1 summarises the net effect of all these branching ratios by showing the fraction of final products observed which belong to each oxide family. Hence on the timescale of the experiments

performed here, $\mathrm{Rh}_{7}^{+/-}$clusters evolve $\mathrm{N}_{2}$ with $100 \%$ efficiency at the $\left[\mathrm{Rh}_{7}(\mathrm{NO})_{2}\right]^{+/-}$and $\left[\mathrm{Rh}_{7} \mathrm{O}_{2}(\mathrm{NO})_{2}\right]^{+/-}$intermediates. However, no such $\mathrm{N}_{2}$ loss is observed at the $\left[\mathrm{Rh}_{7} \mathrm{O}_{4}(\mathrm{NO})_{2}\right]^{+/-}$stage and only simple NO adsorption is observed from this point onwards.

\section{Insert Fig 5 near here}

The largest oxide formed varies with the cluster size. Cluster sizes $n=7,8$ and 9 (as with $n=6$ ), ${ }^{50}$ react to produce tetroxide based final products while $n=10-12$ form predominantly $\left[\mathrm{Rh}_{n} \mathrm{O}_{6}(\mathrm{NO})_{x}\right]^{+/-}$products. Oxides as large as $\mathrm{Rh}_{n} \mathrm{O}_{10}{ }^{+/}$have been observed for $\mathrm{Rh}_{15}{ }^{+/-}$and these become noticeably more prevalent at higher pressures. The interpretation of these findings is 
challenging for there are almost certainly many competing size and structural effects at play. For instance, in order for an NO molecule to adsorb dissociatively there must be a pair of empty adjacent binding sites. The loss of $\mathrm{N}_{2}$ following decomposition of a pair of adsorbed NO molecules provides an additional mechanism for substantial cooling of the product cluster. As a result, the $\mathrm{O}$ atoms which remain on the surface are likely to occupy high coordination sites on the cluster. If sufficiently many $\mathrm{O}$ atoms are thus bound then there will be no pairs of adjacent binding sites left to facilitate the dissociation of an incoming NO molecule which may, as a result adsorb molecularly. Of course, the conclusive signature of dissociative adsorption in these experiments is the loss of $\mathrm{N}_{2}$ which requires the dissociation of at least two NO molecules. By this argument it is possible that the $n=7$ cluster (whose structure is probably based on the $\mathrm{D}_{5 \mathrm{~h}}$ pentagonal dipyramid with ten identical 3-atom sites) ${ }^{59-63}$ "runs out" of enough free adjacent sites either at the $\mathrm{Rh}_{7} \mathrm{O}_{4}$ or $\mathrm{Rh}_{7} \mathrm{O}_{4} \mathrm{NO}$ stage as the only products seen thereafter correspond to successive $\mathrm{NO}$ adsorption with no accompanying $\mathrm{N}_{2}$ desorption. Although we have no conclusive evidence that these final NO molecules adsorb molecularly, such an interpretation is consistent with surface studies which have shown that once the surface is saturated, e.g., with oxygen adatoms, further NO molecules proceed to adsorb molecularly due to the lack of vacant sites required for dissociation..$^{23,25,27}$ In an attempt to determine the nature of the adsorption in reaction products we are currently undertaking FT-ICR collision induced dissociation experiments.

\section{Insert Table 1 near here}

Other factors are clearly also at play. The relative heating effect of nitric oxide adsorption, be it molecularly or dissociatively, is necessarily larger for smaller clusters than it is for larger ones due to the restricted number of vibrational degrees of freedom. This is likely to have a profound effect on 
the mobility of adsorbed atoms on the cluster surface as well as on the structure of the cluster itself which may rearrange. The rate of radiative cooling of the clusters is also size-dependent. This was observed indirectly in the current study in that the degree of oxidation of a given cluster has some weak pressure dependence. For example, at most pressures used in these studies, $\mathrm{Rh}_{12}{ }^{+/-}$favors the formation of $\mathrm{Rh}_{12} \mathrm{O}_{6}{ }^{+/-}$as the main oxide formed. At higher pressures, however, typically $>3 \times 10^{-7}$ mbar, $\mathrm{Rh}_{12} \mathrm{O}_{8}$ products are clearly present. At the higher pressure, the clusters have less time to cool between collisions with NO (which, at pressures of $5 \times 10^{-7} \mathrm{mbar}$, a given cluster experiences at a rate of $c a .20 \mathrm{~s}^{-1}$ ), leading to higher cluster internal energies and thus more mobile surface atoms. As a result there is a greater likelihood of the two nitrogen atoms meeting and desorbing from the cluster surface.

A similar argument accounts for the fact that the larger clusters $(n>16)$ exhibit demonstrably different reactivity to smaller ones. For these clusters (and indeed $\mathrm{Rh}_{13}{ }^{+/}$which is discussed separately below) no $\mathrm{N}_{2}$ desorption is observed. The energy arising from the adsorption of $\mathrm{NO}$ on a large cluster is accommodated in a correspondingly large number of internal degrees of freedom, resulting in only a small rise in the effective cluster "temperature". By contrast, when adsorption is on a smaller cluster the same energy is dissipated into many fewer vibrational modes which i) makes it more likely that the barrier to dissociation will be overcome and ii) that the resulting atomic fragments will be mobile on the surface. A similar change in reactivity for larger $\mathrm{Rh}_{n}{ }^{+/}$clusters with benzene was interpreted by Berg et al. in terms of chemisorption of benzene with subsequent dehydrogenation on the smaller clusters, but only physisorption on cluster sizes above $n=18 .^{40}$

We have fit the kinetics of each cluster to the general mechanism shown in Figure 5 assuming pseudo first order rate behavior for each step. By way of example Figure 6 shows the global kinetic fit for the reactions of the $\mathrm{Rh}_{11}{ }^{+}$cluster, with the final few NO absorption steps omitted for clarity. 
Notwithstanding the simplicity of the mechanism, given the number of steps involved the fits are satisfying and suggest that the major features of the reaction are captured.

\section{Insert Fig 6 near here}

One of the major results of this study is the fact that there was no evidence for the production of by products such as $\mathrm{N}_{2} \mathrm{O}$ or $\mathrm{NO}_{2}$. Desorption of either of these molecules would lead to product peaks in the mass spectrum corresponding to species with an odd number of adsorbed atoms. No such species were observed in any of these experiments. This remarkable ability of rhodium clusters to reduce cleanly $\mathrm{NO}$ at what represent significant coverages, contrasts markedly with the reactions observed on extended surfaces where $\mathrm{N}_{2} \mathrm{O}$ is a common by-product. ${ }^{7,12}$

At the pressures used in these studies most clusters appear to reach an "end-point" in their reaction with nitric oxide, i.e., a product is generated which appears to be saturated and which undergoes no further observable reaction. These species are given in Table 1 for the cations but once again the anions yield remarkably similar results. There is a smooth increase in the total number of adsorbed species with cluster size with the exception of the anomalous behavior at $n=13$. The weak pressure dependence of the largest oxide formed is, of course, reflected in the largest products observed. For $n=15$, for example, the largest product observed at $8.6 \times 10^{-9}$ mbar NO is $\mathrm{Rh}_{15} \mathrm{O}_{6}(\mathrm{NO})_{15}{ }^{+/-}$, whereas at $3.4 \times 10^{-8}$ mbar, products based on the $\mathrm{Rh}_{15} \mathrm{O}_{8}{ }^{+-}$and $\mathrm{Rh}_{15} \mathrm{O}_{10}{ }^{+/-}$oxides can be seen. Nevertheless, where possible, it is tempting to try to infer some structural information on the clusters from their respective end-points. By comparison with the results from extended surfaces we assume that any atomic adsorbates occupy high coordination sites whilst molecularly adsorbed NO molecules are likely to prefer single atom sites. ${ }^{20,29}$ Interestingly for $n=7,8,9,10,12$, the largest products observed have $n+1$ nitric oxide molecules adsorbed. Calculations of likely cluster structures indicate 
that these clusters have only surface atoms. ${ }^{61-65}$ If each surface atom indeed provides a suitable adsorption site for one NO molecule, the one extra NO molecule must either occupy a higher coordination site or is dissociatively adsorbed on the cluster. Either way the high coordination sites are not fully occupied. For example, assuming the pentagonal bipyramid structure for $\mathrm{Rh}_{7}$, only six of the ten equivalent three-atom sites would be occupied - four by the $\mathrm{O}$ atoms resulting from the NO decomposition / $\mathrm{N}_{2}$ loss, plus a dissociatively adsorbed NO molecule. This picture of NO molecules adsorbed at top sites is lent futher weight by the fact that the largest product observed for $\mathrm{Rh}_{13}{ }^{+}$has $12 \mathrm{NO}$ molecules adsorbed - one for each surface atom, see below. Of course this picture assumes that the structural motif of the cluster survives the reactions intact and that adsorbates remain effectively on the surface of the cluster without perturbing it significantly. The validity of this assumption remains to be tested by computation of the likely structures of the reaction products and this is under way in our group.

It is impossible in the current experiments to determine whether or not exchange reactions are taking place. It is conceivable that molecularly adsorbed molecules could exchange with gas-phase molecules resulting in no change in the product mass. We plan to undertake experiments with pulsed isotopically labeled reactants to determine the efficacy of such processes.

\subsection{The anomalous $\mathrm{Rh}_{13}{ }^{+/-}$}

The reaction of the $\mathrm{Rh}_{13}{ }^{+/-}$clusters is markedly different from adjacent cluster sizes as demonstrated in Figure 5. Further illustration of this difference is provided by Figure 7 which shows the time evolution of mass spectra of $\mathrm{Rh}_{13}{ }^{+}$clusters reacting with $\mathrm{NO}$ at $8.6 \times 10^{-9}$ mbar which should be contrasted with the data for $\mathrm{Rh}_{11}{ }^{+}$shown in Figure 1. At this pressure, $\mathrm{Rh}_{13}{ }^{+}$does not react to produce oxides but simply adsorbs NO molecules without obvious signs of decomposition (i.e., loss of $\mathrm{N}_{2}$ ) until a maximum of $12 \mathrm{NO}$ molecules are adsorbed. No larger products are observed at 
even longer reaction times, the distribution of products remaining essentially the same as shown in the bottom spectrum of Figure 7. At higher pressures of $\mathrm{NO}$ some evidence of $\mathrm{N}_{2}$ desorption is apparent but even at the highest pressures used in this study $\left(>5 \times 10^{-7}\right.$ mbar) simple NO adsorption is still the dominant process. By contrast $n=14,15,16$ clusters exhibit very similar reactions to the smaller clusters, evolving $\mathrm{N}_{2}$ in the same way as $\mathrm{Rh}_{11}{ }^{+-}$, and so the discrepancy at $n=13$ does not arise simply as a consequence of the number of available vibrational modes. Instead, its origin is likely to lie in the structure of the $\mathrm{Rh}_{13}$ cluster. Most calculations have found that the $n=13$ cluster size is the first structure to support a non-surface atom, ${ }^{60-65}$ and it seems likely that the unusual behavior of $\mathrm{Rh}_{13}{ }^{+-}$is somehow linked to the unusual stability of its icosahedral structure. The absence of $\mathrm{N}_{2}$ loss could indicate either that $\mathrm{NO}$ does not dissociate on $\mathrm{Rh}_{13}{ }^{+/-}$under these conditions or that there is a significantly higher barrier to the migration of the resulting nitrogen atoms. The fact that the largest product observed is $\mathrm{Rh}_{13}(\mathrm{NO})_{12}{ }^{+}$fits neatly with the idea that there are 12 surface atoms to each of which a single NO molecule can be adsorbed. It would be interesting to try to observe a nitrosyl stretch on $\mathrm{Rh}_{n} \mathrm{NO}$ clusters in general to see if there is a move from dissociative to molecular adsorption with increasing cluster size. Such experiments would be similar to those recently performed by Fielicke et al. on $\mathrm{Au}_{n} \mathrm{NO}^{+}$clusters in which interesting alternations with cluster size were observed for the nitrosyl stretching frequencies. Effects such as these merely reinforce the need for combined spectroscopic and theoretical studies to provide insight into the structures and the reactivity of transition metal clusters. ${ }^{55}$

\section{Insert Fig 7 near here}




\section{Summary and Conclusions}

The decomposition of nitric oxide on small charged rhodium clusters has been studied by Fourier transform ion cyclotron resonance mass spectrometry. The observations are consistent with a sizedependent mechanism common to both cationic and anionic clusters. All clusters studied exhibit simple pseudo first order kinetics with the cations reacting significantly faster than the anions. The trend in the rate of reaction with cluster size, as well as the overall magnitude of the reactive rate constants is reasonably well modeled by the surface charge capture model proposed by Beyer.

The smaller clusters studied, $n=7-16$, mostly undergo dissociative adsorption of NO in the early stages of reaction resulting in $\mathrm{N}_{2}$ desorption and the formation of even-oxides. For $n<13$ this process continues until a critical (size-dependent) oxide cluster is produced after which further NO molecules adsorb without further $\mathrm{N}_{2}$ loss. $n=14-16$ react to form products based on a small range of oxides whilst larger rhodium clusters (and the anomalous $n=13$ ) simply adsorb nitric oxide without apparent $\mathrm{N}_{2}$ desorption until saturated. A simple multi-stage mechanism has been proposed which accounts for all the major findings of these studies. No evidence was observed for the generation of either $\mathrm{N}_{2} \mathrm{O}$ or $\mathrm{NO}_{2}$ on any clusters studied despite the fact that these molecules are significant by products of the same reaction on extended surfaces.

\section{Acknowledgements}

The authors are grateful to the UK Engineering and Physical Research Council (EPSRC) for financial support under the Special Equipment Initiative, grant GR/S03966/01 and an Advanced Research Fellowship for SRM. MLA is further grateful to EPSRC for her studentship. We gratefully acknowledge the advice and expertise offered by Dr. Martin Beyer and Dr. Petru Balaj of the Bondybey group at the Technische Universität München during construction of the cluster source and subsequent integration with the FT-ICR instrument. 


\section{REFERENCES}

(1) DeLouise, L. A.; Winograd, N. Surf. Sci. 1985, 159, 199.

(2) Armentrout, P. B. Ann. Rev. Phys. Chem. 2001, 52, 423.

(3) Knickelbein, M. B. Ann. Rev. Phys. Chem. 1999, 50, 79.

(4) Hickman, D. A.; Schmidt, L. D. Science 1993, 259, 343.

(5) Zhdanov, V. P.; Kasemo, B. Surf. Sci. Rep. 1997, 29, 31.

(6) Obuchi, A.; Ohi, A.; Nakamura, M.; Ogata, A.; Mizuno, K.; Obuchi, H. Appl. Catal. $B$ 1993, 2, 71 .

(7) Hamada, H.; Kintaichi, Y.; Sasaki, M.; Ito, T.; Tabata, M. Appl. Catal. 1991, 75, L1.

(8) Taylor, K. C.; Schlatter, J. C. J. Catal. 1980, 63, 53.

(9) Burch, R.; Breen, J. P.; Meunier, F. C. Appl. Catal. B 2002, 39, 283.

(10) Parvulescu, V. I.; Grange, P.; Delmon, B. Catal. Today 1998, 46, 233.

(11) Brown, W. A.; King, D. A. J. Phys. Chem. A 2000, 104, 2578.

(12) Chin, A. A.; Bell, A. T. J. Phys. Chem. 1983, 87, 3700.

(13) Makeev, A. G.; Slinko, M. M. Surf. Sci. Lett. 1996, 359, L467.

(14) Bavel, A. P. v.; Hermse, C. G. M.; Hopstaken, M. J. P.; Jansen, A. P. J.; Lukkien, J.

J.; Hilbers, P. A. J.; Niemantsverdriet, J. W. Phys. Chem. Chem. Phys. 2004, 6, 1830.

(15) Siokou, A.; Hardeveld, R. M. v.; Niemantsverdriet, J. W. Surf. Sci. 1998, 402-404, 110.

(16) Kao, C.-T.; Blackman, G. S.; Howe, M. A. v.; Somorjai, G. A.; Chan, C.-M. Surf. Sci. 1989, 224, 77.

(17) Castner, D. G.; Sexton, B. A.; Somorjai, G. A. Surf. Sci. 1978, 71, 519.

(18) Liao, D.; Glassford, K. M.; Ramprasad, R.; Adams, J. B. Surf. Sci. 1998, 415, 11.

(19) Loffreda, D.; Simon, D.; Sautet, P. J. Chem. Phys. 1998, 108, 6447.

(20) Loffreda, D.; Simon, D.; Sautet, P. J. Catal. 2003, 213, 211.

(21) Zaera, F.; Gopinath, C. S. J. Mol. Catal. A: Chem. 2001, 167, 23.

(22) Comelli, G.; Dhanak, V. R.; Pangher, N.; Paolucci, G.; Kiskinova, M.; Rosei, R. Surf. Sci. 1994, 317, 117.

(23) Borg, H. J.; Reijerse, J. F. C.-J. M.; Santen, R. A. v.; Niemantsverdriet, J. W. J. Chem. Phys. 1994, 101, 10052.

(24) Xu, H.; Ng, K. Y. S. Surf. Sci. 1996, 365, 779.

(25) Villarrubia, J. S.; Ho, W. J. Chem. Phys. 1987, 87, 750.

(26) Bowker, M.; Guo, Q.; Joyner, R. W. Surf. Sci. 1991, 257, 33

(27) Hopstaken, M. J. P.; Niemantsverdriet, J. W. J. Phys. Chem. B 2000, 104, 3058.

(28) Inderwildi, O. R.; Lebiedz, D.; Deutschmann, O.; Warnatz, J. J. Chem. Phys. 2005, 122,154702 .

(29) Loffreda, D.; Delbecq, F.; Simon, D.; Sautet, P. J. Chem. Phys. 2001, 115, 8101.

(30) Kim, Y. J.; Thevuthasan, S.; Herman, G. S.; Peden, C. H. F.; Chambers, S. A.;

Belton, D. N.; Permana, H. Surf. Sci. 1996, 359, 269.

(31) Root, T. W.; Fisher, G. B.; Schmidt, L. D. J. Chem. Phys. 1986, 85, 4687.

(32) Root, T. W.; Fisher, G. B.; Schmidt, L. D. J. Chem. Phys. 1986, 85, 4679.

(33) Root, T. W.; Schmidt, L. D.; Fisher, G. B. Surf. Sci. 1983, 134, 30.

(34) Schmatlock, V.; Jirka, I.; Kruse, N. Surf. Sci. Lett. 1993, 297, L100.

(35) Schmatlock, V.; Jirka, I.; Kruse, N. J. Chem. Phys. 1994, 100, 8471.

(36) Esch, F.; Baraldi, A.; Comelli, C.; Lizzit, S.; Kiskinova, M.; Cobden, P. D.;

Nieuwenhuys, B. E. J. Chem. Phys. 1999, 110, 4013. 
(37) Schmatlock, V.; Jirka, I.; Heinze, S.; Kruse, N. Surf. Sci. 1995, 331-333, 23.

(38) Balteanu, I.; Achatz, U.; Balaj, O. P.; Fox, B. S.; Beyer, M. K.; Bondybey, V. E. Int. J. Mass Spectrom. 2003, 229, 61.

(39) Balteanu, I.; Balaj, O. P.; Fox, B. S.; Rodrigues, P.; Barros, M. T.; Moutinho, A. M. C.; Costa, M. L.; Beyer, M. K.; Bondybey, V. E. Organometallics 2004, 23, 1978.

(40) Berg, C.; Beyer, M.; Schindler, T.; Niedner-Schatteburg, G.; Bondybey, V. E. J. Chem. Phys. 1996, 104, 7940.

(41) Adlhart, C.; Uggerud, E. J. Chem. Phys. 2005, 123, 214709.

(42) Fielicke, A.; Helden, G. v.; Meijer, G.; Pedersen, D. B.; Simard, B.; Rayner, D. M. J. Phys. Chem. A 2004, 108, 14591.

(43) Balteanu, I.; Balaj, O. P.; Beyer, M. K.; Bondybey, V. E. Int. J. Mass Spectrom.

2005.

(44) Albert, G.; Berg, C.; Beyer, M.; Achatz, U.; Joos, S.; Niedner-Schatteburg, G.;

Bondybey, V. E. Chem. Phys. Lett. 1997, 268, 235.

(45) Koszinowski, K.; Schlangen, M.; Schroder, D.; Schwarz, H. Int. J. Mass Spectrom. 2004, $237,19$.

(46) Alford, J. M.; Weiss, F. D.; Laaksonen, R. T.; Smalley, R. E. J. Phys. Chem. 1986, 90,4480 .

(47) Elkind, J. L.; Weiss, F. D.; Alford, J. M.; Laaksonen, R. T.; Smalley, R. E. J. Chem. Phys. 1988, 88, 5215.

(48) Nakatsuji, T.; Komppa, V. Catal. Today 2002, 75, 407.

(49) Kummerlowe, G.; Beyer, M. K. Int. J. Mass Spectrom. 2005, $244,84$.

(50) Ford, M. S.; Anderson, M. L.; Barrow, M. P.; Woodruff, D. P.; Drewello, T.; Derrick, P. J.; Mackenzie, S. R. Phys. Chem. Chem. Phys. 2005, 7, 975.

(51) Berg, C.; Schindler, T.; Niedner-Schatteburg., G.; Bondybey, V. E. J. Chem. Phys. 1995, 102, 4870 .

(52) Laskin, J.; Byrd, M.; Futrell, J. Int. J. Mass Spectrom. 2000, 195/196, 285.

(53) Smith, D.; Adams, N. G. Phys. Rev. A 1981, 23, 2327.

(54) Harding, D.; Ford, M. S.; Walsh, T. R.; Mackenzie, S. R. in prep 2006.

(55) Ford, M. S.; Mackenzie, S. R. J. Chem. Phys. 2005, 123, 084308.

(56) Zakin, M. R.; Brickman, R. O.; Cox, D. M.; Kaldor, A. J. Chem. Phys. 1988, 88, 3555.

(57) Berg, C.; Beyer, M.; Achatz, U.; Joos, S.; Niedner-Schatteburg, G.; Bondybey, V. E. J. Chem. Phys. 1998, 108, 5398.

(58) Berg, C.; Schindler, T.; Lammers, A.; Niedner-Schatteburg, G.; Bondybey, V. E. J. Phys. Chem. 1995, 99, 15497.

(59) Aquilera-Granja, F.; Rodriquez-Lopez, J. L.; Michaelian, K.; Berlanga-Ramirez, E. O.; Vega, A. Phys. Rev. B 2002, 66, 224410.

(60) Jinlong, Y.; Toigo, F.; Kelin, W. Phys. Rev. B 1994, 50, 7915.

(61) Futschek, T.; Marsman, M.; Hafner, J. J. Phys.: Condens. Matter 2005, 17, 5927.

(62) Wang, L.; Ge, Q. Chem. Phys. Lett. 2002, 366, 368.

(63) Reddy, B. V.; Bayak, S. K.; Khanna, S. N.; Rao, B. K.; Jena, P. Phys. Rev. B 1999, $59,5214$.

(64) Barreteau, C.; Guirado-Lopez, R.; Spanjaard, D.; Desjonqueres, D.; Oles, A. M. Phys. Rev. B 2000, 61, 7781 .

(65) Chien, C.-H.; Blaisten-Barojas, E.; Pederson, M. R. J. Chem. Phys. 2000, 112, 2301. 


\section{FIGURE CAPTIONS}

Figure 1. Time evolution of the mass spectra of $\mathrm{Rh}_{11}{ }^{+}$clusters exposed to $c a .8 .6 \times 10^{-9}$ mbar NO. The kinetics can be fit well assuming a mechanism involving the dissociative adsorption of two NO molecules on the bare cluster followed by subsequent desorption of molecular nitrogen generating $\left[\mathrm{Rh}_{11} \mathrm{O}_{2}\right]^{+}$. This process repeats generating the higher order even oxides $\left[\mathrm{Rh}_{11} \mathrm{O}_{4}\right]^{+}$and $\left[\mathrm{Rh}_{11} \mathrm{O}_{6}\right]^{+}$ after which no further $\mathrm{N}_{2}$ is desorbed and $\mathrm{NO}$ is assumed to adsorb molecularly.

Figure 2. Detailed view of the FT-ICR mass spectra of $\mathrm{Rh}_{11}{ }^{+}$clusters exposed to $8.6 \times 10^{-9}$ mbar NO for 5 seconds. The arrows indicate the key early steps in the mechanism responsible for the decomposition of chemisorbed NO.

Figure 3. 1 st order kinetic data for the reaction of $\mathrm{Rh}_{11}{ }^{+/-}$clusters with nitric oxide $\left(8.6 \times 10^{-9}\right.$ mbar $)$. Symbols denote actual data (filled squares $\mathrm{Rh}_{11}$, open squares $\mathrm{Rh}_{11}{ }^{+}$) and the lines indicate fits to single exponential decays from which pseudo first order rate constants can be extracted. The observation that the cation reacts slightly more quickly than the anion is common to all cluster sizes studied.

Figure 4. Absolute rate constants for the reaction $\mathrm{Rh}_{n}{ }^{+/-}+\mathrm{NO}$ as a function of cluster size. Open squares represents the cationic clusters, filled squares the anions. Also shown are the calculated rate constants assuming a hard sphere geometrical cross-section (dashed line), classical average dipole orientation theory (dotted line), the hard-sphere average dipole orientation model (dot-dashed line) and the surface charge capture model (solid line). See text for details. 
Figure 5. A general reaction mechanism for all sizes investigated. For the specific illustrative cluster sizes shown in a) to e), the size of the arrows represents the relative branching ratio for desorption of $\mathrm{N}_{2}$ (vertical) versus sequential $\mathrm{NO}$ adsorption. The reaction mechanism is essentially identical for the anionic and cationic versions of the same cluster size.

Figure 6. Example global kinetic fit to the mechanism shown in Figure 5 for the reactions of nitric oxide on $\mathrm{Rh}_{11}{ }^{+}$where $(x, y)$ refers to species $\left[\mathrm{Rh}_{11} \mathrm{O}_{y}(\mathrm{NO})_{x}\right]^{+}$. The final steps, involving sequential NO adsorption, are omitted for clarity.

Figure 7. Time evolution of the mass spectra of $\mathrm{Rh}_{13}{ }^{+}$clusters exposed to $8.6 \times 10^{-9}$ mbar nitric oxide. Unlike the smaller and adjacent clusters there is no evidence of $\mathrm{N}_{2}$ evolution resulting in oxide clusters. 


\section{TABLES.}

Table 1. Summary of the branching ratios for the reaction of the cationic clusters studied at a nitric oxide pressure of $8.6 \times 10^{-9}$ mbar. The numbers represent the fraction of final products built upon each oxide cluster. See text for details. 


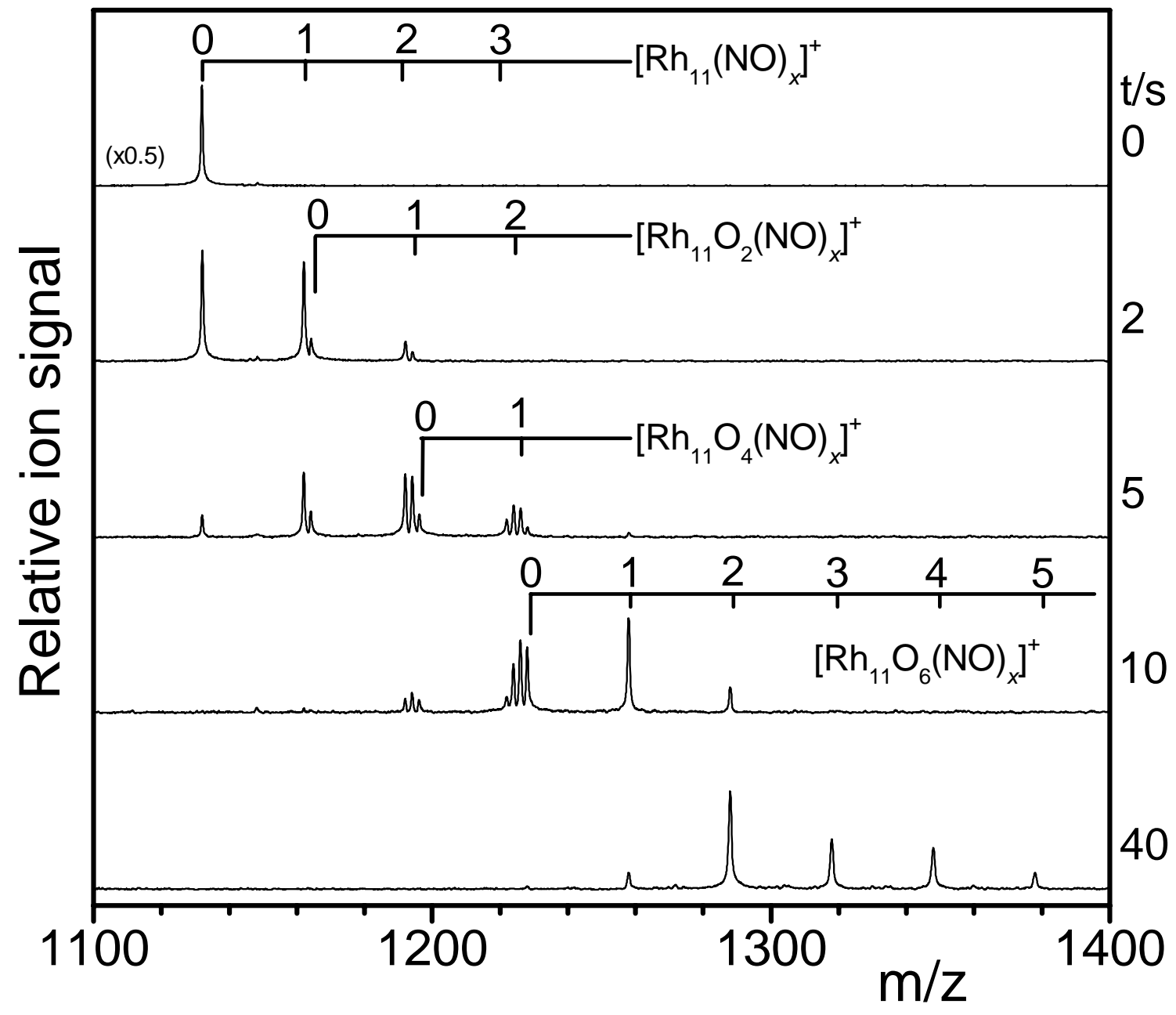

Figure 1 


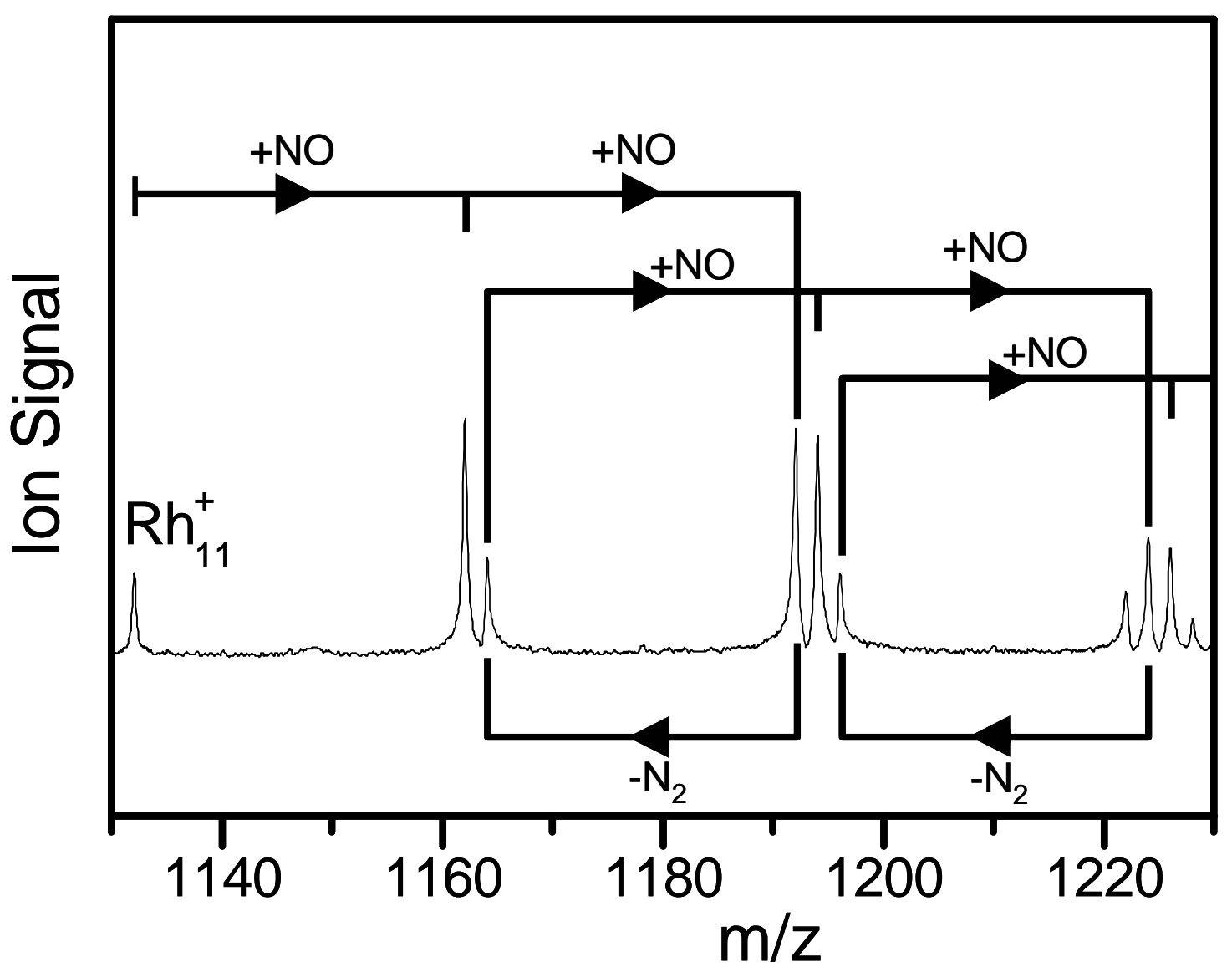

Figure 2 


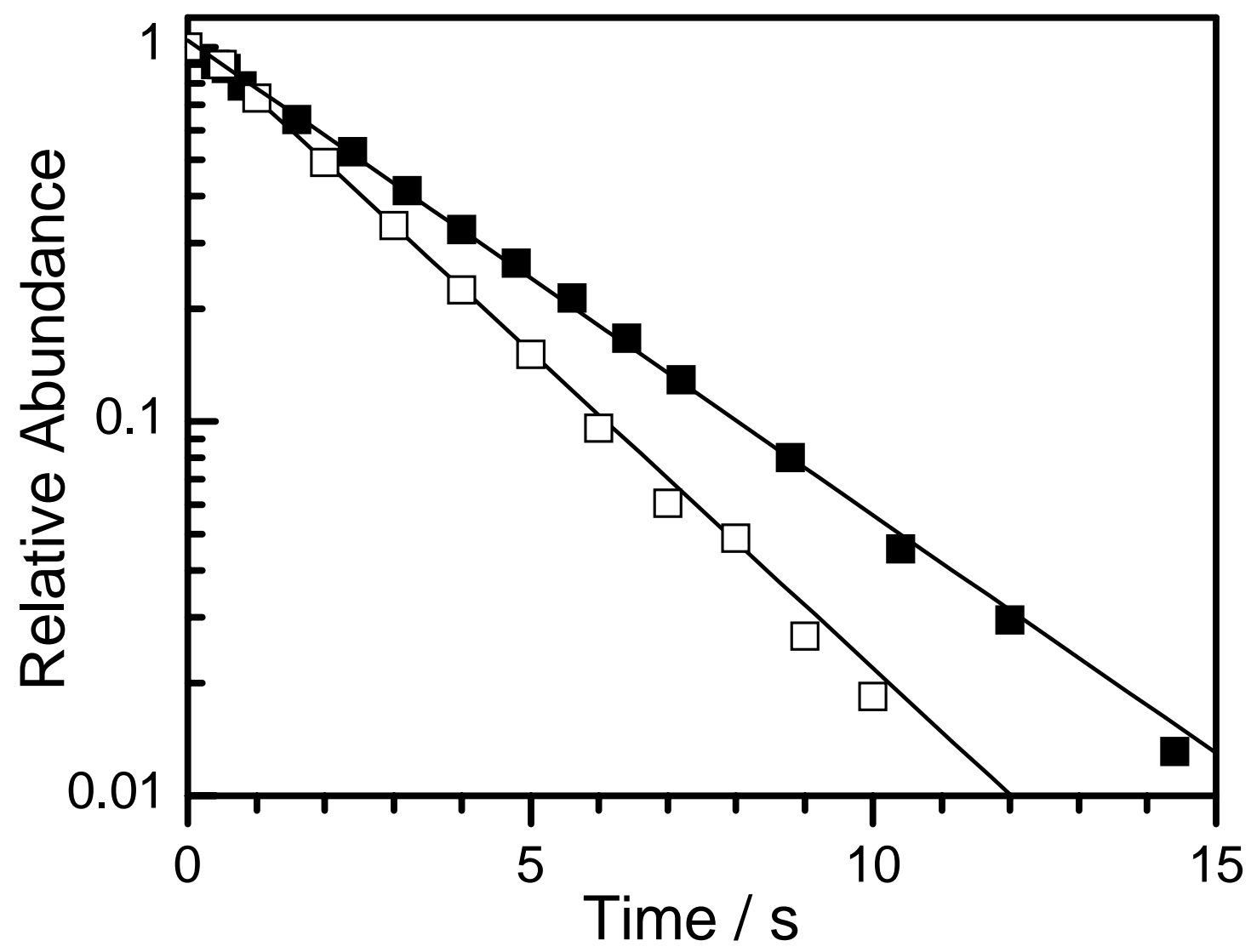

Figure 3 


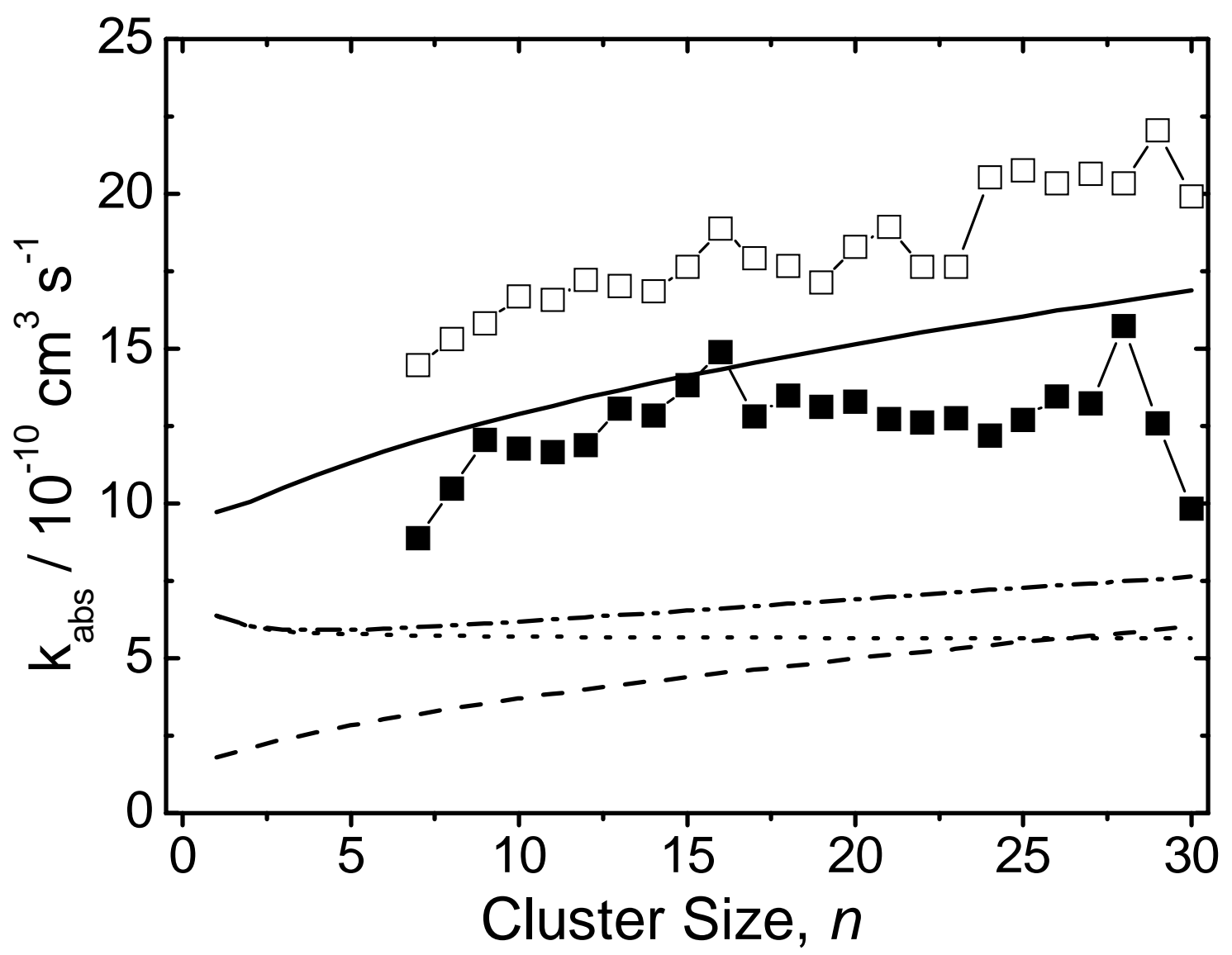

Figure 4 


\section{Sequential NO adsorption}

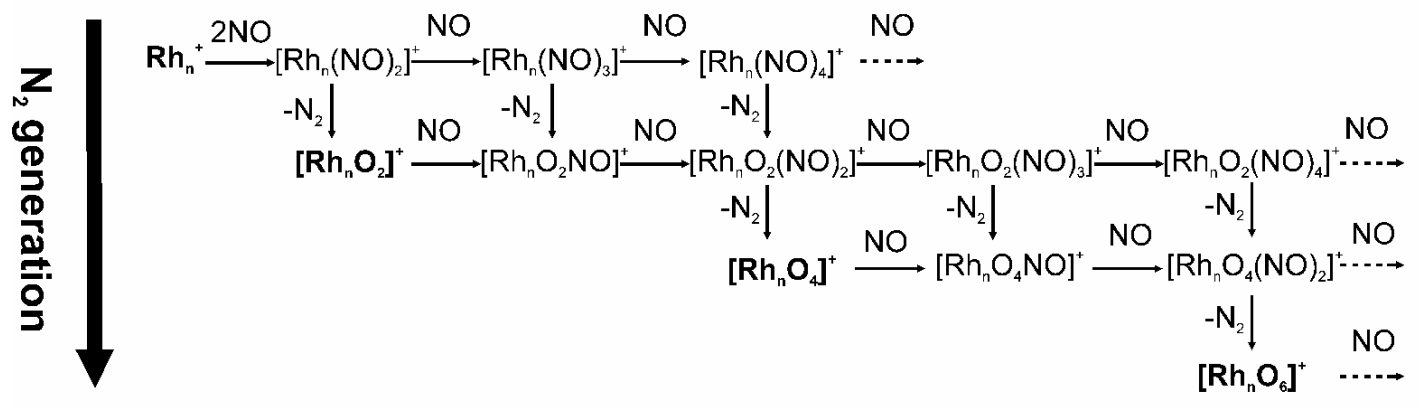

(a) $\mathrm{Rh}_{7}{ }^{+}$

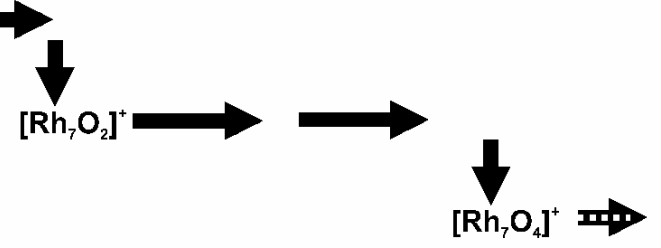

(b) $\mathrm{Rh}_{9}{ }^{+}$

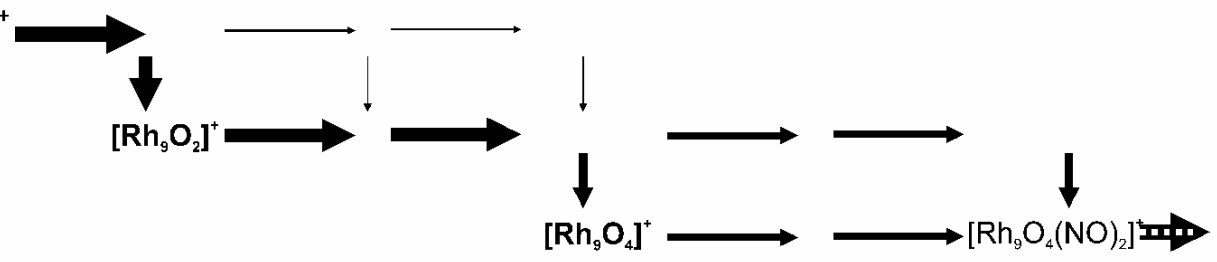

(c) $\mathrm{Rh}_{11}{ }^{+}$
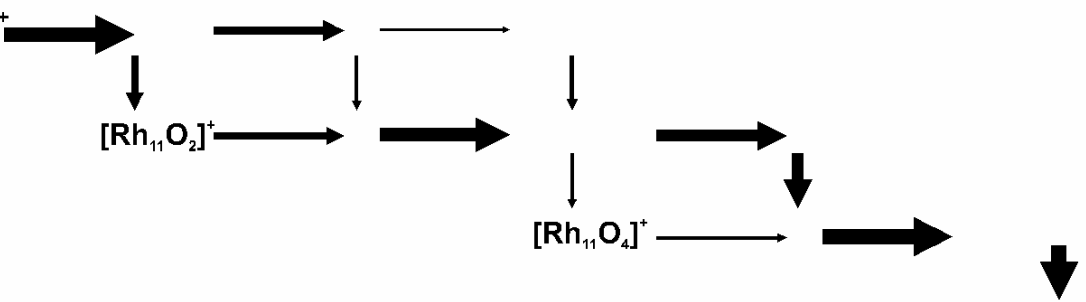

$\left[\mathrm{Rh}_{11} \mathrm{O}_{6}\right]^{+}$皿

(d) $\mathrm{Rh}_{13}{ }^{+} \mathrm{mm} \boldsymbol{m}$

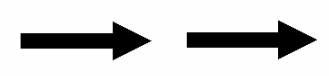

$\left[\mathrm{Rh}_{13}(\mathrm{NO})_{6}\right]^{+} \mathbf{m}$

(e) $\mathrm{Rh}_{14}$

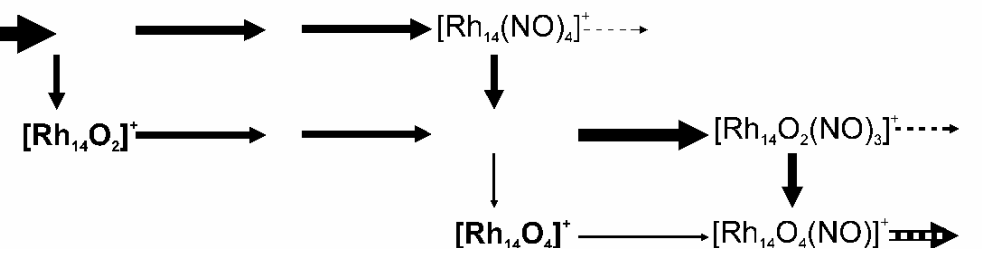

Figure 5

(double column figure) 

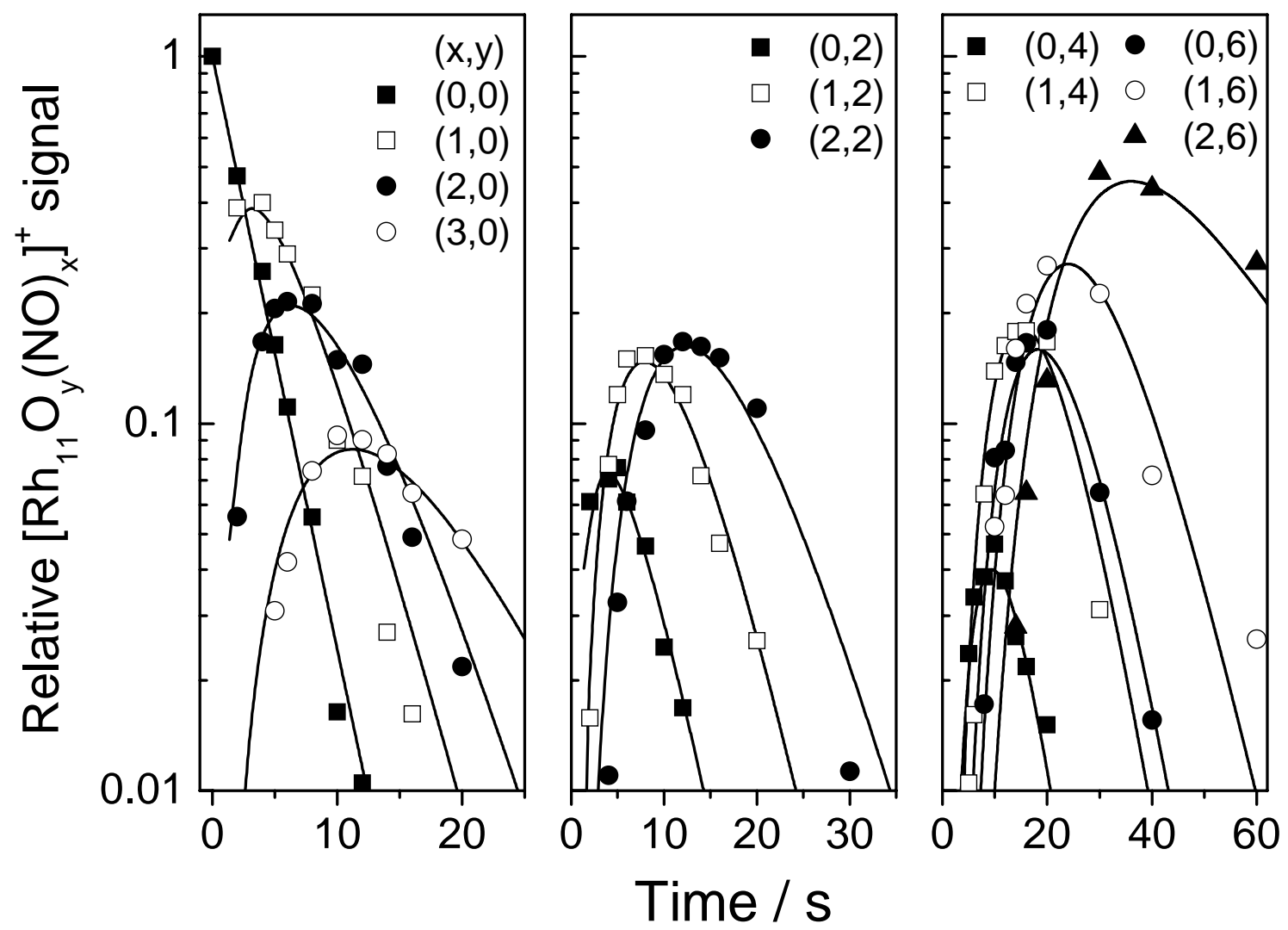

Figure 6 


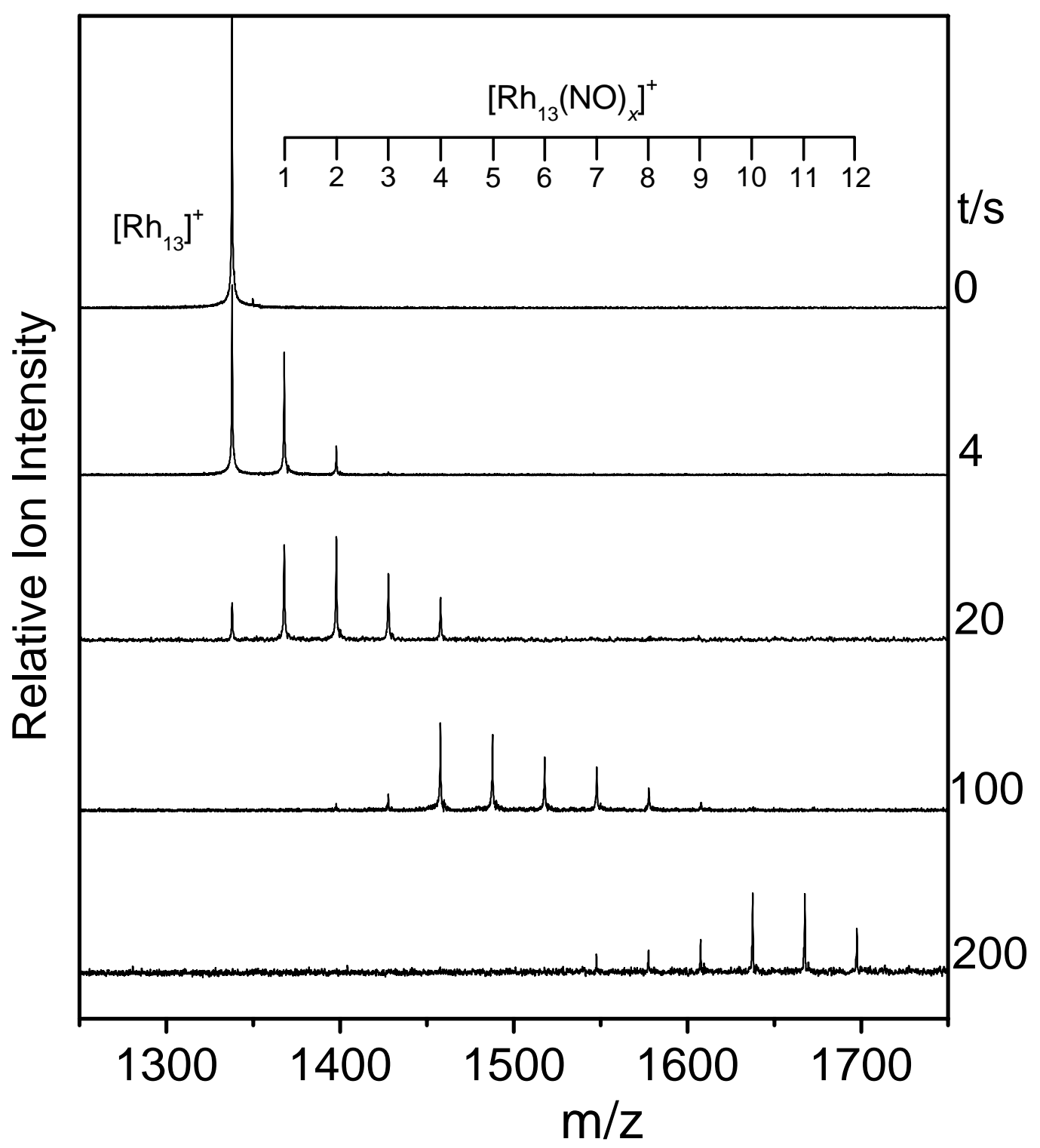

Figure 7 
Table 1

\begin{tabular}{|c|c|c|c|c|c|c|}
\hline \multirow{2}{*}{$\begin{array}{l}\text { Cluster } \\
\text { size, } n\end{array}$} & \multicolumn{5}{|c|}{$\mathrm{Rh}_{n} \mathrm{O}_{y}(\mathrm{NO})_{x}{ }^{+}$} & \multirow{2}{*}{$\begin{array}{l}\text { Largest product } \\
\text { observed }\end{array}$} \\
\hline & $\mathrm{y}=0$ & 2 & 4 & 6 & 8 & \\
\hline 7 & - & - & 1 & - & - & $\mathrm{Rh}_{7} \mathrm{O}_{4}(\mathrm{NO})_{8}$ \\
\hline 8 & - & - & 1 & - & - & $\mathrm{Rh}_{8} \mathrm{O}_{4}(\mathrm{NO})_{9}$ \\
\hline 9 & - & 0.12 & 0.86 & 0.02 & - & $\mathrm{Rh}_{9} \mathrm{O}_{4}(\mathrm{NO})_{10}$ \\
\hline 10 & - & - & - & 1 & - & $\mathrm{Rh}_{10} \mathrm{O}_{6}(\mathrm{NO})_{11}$ \\
\hline 11 & - & - & - & 1 & - & $\mathrm{Rh}_{11} \mathrm{O}_{6}(\mathrm{NO})_{11}$ \\
\hline 12 & - & 0.04 & 0.12 & 0.84 & - & $\mathrm{Rh}_{12} \mathrm{O}_{6}(\mathrm{NO})_{13}$ \\
\hline 13 & 1 & - & - & - & - & $\mathrm{Rh}_{13}(\mathrm{NO})_{12}$ \\
\hline 14 & - & 0.43 & 0.57 & - & - & $\mathrm{Rh}_{14} \mathrm{O}_{4}(\mathrm{NO})_{8}$ \\
\hline 15 & 0.08 & 0.21 & 0.35 & 0.36 & - & $\mathrm{Rh}_{15} \mathrm{O}_{6}(\mathrm{NO})_{15}$ \\
\hline 16 & 0.02 & 0.11 & 0.16 & 0.19 & 0.52 & $\mathrm{Rh}_{16} \mathrm{O}_{8}(\mathrm{NO})_{17}$ \\
\hline $17-30$ & 1 & - & - & - & - & $\mathrm{Rh}_{\mathrm{n}}(\mathrm{NO})_{x}$ \\
\hline
\end{tabular}

